\title{
Docetaxel-Loaded Cholesterol-PEG Co-Modified Poly (n-Butyl) Cyanoacrylate Nanoparticles for Antitumor Drug Pulmonary Delivery: Preparation, Characterization, and in vivo Evaluation
}

This article was published in the following Dove Press journal:

International Journal of Nanomedicine

\author{
Xiao $\mathrm{Hu}^{\prime}$ \\ Feifei Yang ${ }^{2}$ \\ Yonghong Liao $\mathbb{D}^{2}$ \\ Lin $\mathrm{Li}^{\mathrm{I}}$ \\ Guoguang Zhao ${ }^{3}$ \\ Lan Zhang'
}

'Department of Pharmacy, Xuanwu Hospital of Capital Medical University, Beijing Institute for Brain Disorders, Key Laboratory for Neurodegenerative Diseases of Ministry of Education, Beijing I00053, People's Republic of China; ${ }^{2}$ Institute of Medicinal Plant

Development, Chinese Academy of Medical Sciences \& Peking Union Medical College, Beijing 100193, People's Republic of China; ${ }^{3}$ Department of Neurosurgery, Xuanwu Hospital of Capital Medical University, Beijing 100053, People's Republic of China
Correspondence: Guoguang Zhao; Lan Zhang

Email ggzhao@vip.sina.com; lanizhg@|26.com
Background and Aim: Polymeric nanoparticles (NPs) have received much attention as promising carrier systems in lung cancer and brain metastases.

Methods: Here, for the first time, we investigated the feasibility of using inhaled cholesterol-PEG co-modified poly (n-butyl) cyanoacrylate NPs (CLS-PEG NPs) of docetaxel (DTX) for sustained pulmonary drug delivery in cancer metastasis.

Results: Spray-dried or freeze-dried NPs yielded sustained drug release in vitro. In vitro inhalation evaluation data indicated that the inhalation formulation had better inhalability. Compared with intravenous (IV) administration, pharmacokinetic data suggested that the inhalation formulation prolonged plasma concentration of DTX for greater than $24 \mathrm{~h}$ and is more quickly and completely absorbed into the rat lung after intratracheal (IT) administration. Furthermore, freeze-dried powders were found to increase the $t_{1 / 2}$ and area under curve (AUC) by 2.3 and 6.5 fold compared to the free drug after IT administration, and spray-dried powders were found to increase the $t_{1 / 2}$ and AUC by 3.4 and 8.8 fold, respectively. After pulmonary administration of the inhalation formulation, DTX appeared to prolong the pulmonary absorption time. In addition, the inhalation formulation was distributed to the brain in a sustained release manner.

Conclusion: These experimental results demonstrated that freeze- and spray-dried powders have the potential for pulmonary sustained release, and they also have the potential to be used as a novel treatment for the delivery of drugs that pass through the air-blood barrier and enter the brain and are efficient carriers for the treatment of brain metastasis.

Keywords: pulmonary delivery, docetaxel, lung cancer, spray-drying, dry powder

\section{Introduction}

Lung cancer is one of the leading causes of cancer-related deaths worldwide. Lung cancer is divided into small cell lung cancer and non-small cell lung cancer (NSCLC), and the latter accounts for $80-90 \%$ of all lung cancer. ${ }^{1}$ In contrast to other common solid organ cancers, owing to the lack of typical clinical symptoms, many patients diagnosed with lung cancer are already in the advanced stage of the disease and lose the opportunity for surgical treatment. Presently, conventional treatment options including surgical techniques, radiotherapy, immunotherapy, and chemotherapy are the normal therapy regimens for lung cancers. However, the overall 5-year survival rate for patients with lung cancer is approximately $15 \%{ }^{2}$ 
Consequently, there is a strong need to develop a treatment regimen that can improve the effectiveness and minimize the systemic side effects.

The lung is a directly accessible organ from the outside. Thus, inhalation therapy represents an attractive application route for the targeted delivery of medications to their desired site of action. The lung provides high absorption and large surface area $\left(100 \mathrm{~m}^{2}\right)$ so that inhalation therapy has several advantages over other routes of administration, like quick absorption, fast onset of action, extended selectivity, high lung concentration, and most importantly, it can diminish systemic exposure to drugs and decrease systemic toxicity. ${ }^{3-6}$

Nanoparticles (NPs) are promising candidates for the treatment of lung cancers because of their biocompatibility, ease of surface modification, localized action and reduced systemic toxicity. ${ }^{7-11}$ NPs have also gathered much attention in the tumor therapy because of their high drug loading capability, stability in vitro or in vivo, and controlled release. ${ }^{12-16}$ NPs can protect the drug loaded from rapid degradation after entering the human body, thus increase the stability of the drug. Moreover, the release rate and time of NPs can be adjusted by modifying the structure and function of the carrier, which can prolong the action time of the drug in the body and achieve the sustained release effect.

Owing to its anti-proliferative mechanism, docetaxel (DTX) could be used for the treatment of several tumors, including breast, ovarian, prostate, and non-small cell lung cancer, by obstructing the microtubule depolymerization of free tubulins. ${ }^{17-21}$ However, owing to its poor physicochemical and biopharmaceutical properties, which include poor solubility, low oral bioavailability, renal clearance, and non-selective distribution, the use of DTX is highly obstructed in clinical applications. ${ }^{17}$ Nowadays, the commercial preparation Taxotere is DTX formulated with polysorbate 80 , which is diluted with ethanol and further diluted by $5 \%$ dextrose solution or saline. Unfortunately, polysorbate 80 leads to side-effects like severe hypersensitivity reactions and peripheral neuropathy. In our previous studies, a novel co-modified drug delivery system, on the basis of cholesterol and polyethylene glycol (PEG) was developed to target tumor-associated macrophages through the blood-brain barrier (BBB). ${ }^{22}$

Therefore, the main objective of this study was to develop a novel pulmonary system, using cholesterolPEG dual modified poly (ethylene glycol)-poly (lactide) NPs (CLS-PEG NPs), and determine aerodynamic assessment of fine particles in vitro. Finally, we included an analysis of the pharmacokinetics and tissue distribution of CLS-PEG NPs. The further objective was to verify the hypothesis that DTX-loaded CLS-PEG NPs by the pulmonary route were useful carriers for achieving sustained and efficient translocation of DTX across the air-blood barrier into the lung, with subsequent spreading to the brain.

\section{Materials and Methods}

\section{Materials}

DTX (Cat. No. 1005) was obtained from Huafeng Lianbo Technology Co., Ltd. (Beijing, China). 1,1-Dioctadecyl3,3,3,3-tetramethylindotricarbocyanine (DiR, Cat. No. 22070) was purchased from AAT Bioquest. Inc. (Sunnyvale, CA, US). $\mathrm{PEG}_{20000}$ (Cat. No. 81300), leucine (Cat. No. L8000) and cholesterol (water soluble, Cat. No. C8667) were purchased from Sigma-Aldrich (St. Louis, MO, USA). N-butyl cyanoacrylate (Cat. No. FK-VE287) was donated by Shun-Kang Biotechnology Co., Ltd. (Beijing, China). HPLC grade acetonitrile (ACN, Cat. No. 271004) was obtained from Merck (Darmstadt, Germany). All additional solvents were of analytical grade.

\section{Preparation of Drug Powders and Solutions \\ Preparation of CLS-PEG NPs}

CLS-PEG NPs loaded DTX were prepared as reported previously. ${ }^{17}$ Briefly, CLS-PEG NPs were prepared by an emulsion polymerization method. Dextran $\left(70 \mathrm{kDa} \mathrm{M}_{\mathrm{r}}\right.$, catalog numbers: 44886) was dissolved in hydrochloric acid (pH 1) with constant stirring, using a magnetic bar. Thereafter, n-butyl cyanoacrylate was added in a dropwise manner to obtain a $1 \% \mathrm{v} / \mathrm{v}$ NP suspension. The solution was and stirred continuously for $4 \mathrm{~h}$ at $500 \mathrm{rpm}$. Next, 1\% (w/v) DTX was added and the stir speed increased to $750 \mathrm{rpm}$ for $2.5 \mathrm{~h}$, to facilitate NP formation. Finally, the mixture was neutralized with sodium hydroxide $(0.1 \mathrm{~N})$ and stirred for an additional $1 \mathrm{~h}$. NPs were filtered through a $0.45 \mu \mathrm{m}$ nylon membrane, and filtrates dialyzed to remove unreacted materials and freeze-dried. Lyophilized NPs were re-suspended in phosphate buffered saline (PBS) with $(1 \% \mathrm{w} / \mathrm{v})$ cholesterol and stirred for an additional $30 \mathrm{~min}$. Resulting CLS-PEG NPs were dialyzed to dislodge unreacted materials. 


\section{Preparation of Dry Powders Containing CLS-PEG NPs}

A Mini Spray Dryer B-290 (BUCHI Labortechnik AG, Flawil, Switzerland) was used for the spray-drying process, to form dry powders containing CLS-PEG NPs. Elastic parameters include inlet and outlet temperature, solution pump flow rate, and the aspirator partial vacuum. Here, the inlet air temperature was $100^{\circ} \mathrm{C}$, the outlet temperature was approximately $60 \square 65^{\circ} \mathrm{C}$, the pump flow rate was $3 \mathrm{~mL} / \mathrm{min}$, the aspirator was set to $0.45 \mathrm{~m}^{3} / \mathrm{min}$, and the atomizing air flow rate was $600 \mathrm{~L} / \mathrm{h}$. Leucine $(50 \mathrm{mg})$ was dissolved in distilled water and mixed with a suspension of $0.5 \mathrm{~g}$ NPs in $10 \mathrm{mg}$ DTX and was subsequently pumped into the spray dryer. Following spraydrying, the powders were stored in a dryer under light protection.

\section{Preparation of Atomizing Solution Containing CLS-PEG NPs}

The freeze-drying process to form the atomizing solution containing CLS-PEG NPs was performed using a freezedryer (Virtis AdVantage 2.0 ES, USA). The CLS-PEG NPs were prefrozen at $-80^{\circ} \mathrm{C}$ for $24 \mathrm{~h}$. Thereafter, CLS-PEG NPs were frozen at $-45^{\circ} \mathrm{C}$ for $6 \mathrm{~h}$. During the primary drying phase, a temperature of $-30^{\circ} \mathrm{C}$ was retained for $18 \mathrm{~h},-20^{\circ} \mathrm{C}$ maintained for $5 \mathrm{~h}$, and $0^{\circ} \mathrm{C}$ maintained for $4 \mathrm{~h}$. During the secondary drying phase, the temperature was raised to $20^{\circ} \mathrm{C}$ and maintained for $4 \mathrm{~h}$. Samples were stored at $-20^{\circ} \mathrm{C}$ prior to analysis.

\section{Characterization of DTX-Loaded CLS-PEG NPs}

\section{Particle Size and Zeta Potential}

Particle size and zeta potential of NPs before and after spray- or freeze-drying, obtained by reconstitution, were surveyed by dynamic light scattering using a Zeta sizer Nano ZS (Malvern Instruments Ltd., UK). Tests were performed in triplicate.

\section{Drug Loading and Encapsulation Efficiency}

The amount of DTX was dictated by the CLS-PEG NP total content and calculated using an HPLC assay. The e2695 HPLC system was equipped with a Waters 2487 dual-channel UV detector and a C-18 column (250 $\mathrm{mm} \times$ $4.6 \mathrm{~mm}, 5 \mu \mathrm{m}$, Phenomenex Inc., Torrance, CA, USA). The isocratic mobile phase was composed of $\mathrm{ACN} / \mathrm{H}_{2}$ $\mathrm{O}(55: 45 \mathrm{v} / \mathrm{v})$ at $1.0 \mathrm{~mL} / \mathrm{min}$ and detected at $230 \mathrm{~nm}$. The amount of loaded DTX was determined as the total content in NPs. Prior to HPLC analysis, NPs was disrupted the structure by adding $2 \mathrm{~mL}$ of acetonitrile. The amount of the encapsulated DTX was referred to the remaining content after ultra-filtration. Briefly, $200 \mu \mathrm{L}$ of NPs were transferred to an ultra-filtration tube (MWCO $2000 \mathrm{Da}$, Sartorius Stedim Biotech, Goettingen, Germany) and centrifuged at $4000 \times g$ for $20 \mathrm{~min}$.

Drug loading (DL) and the encapsulation efficiency (EE) were deliberated as follows:

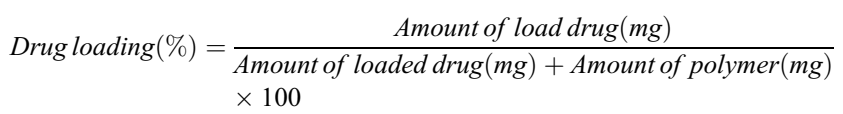
Encapsulation efficiency $(\%)=\frac{\text { Amount o encapsulated drug }(\mathrm{mg})}{\text { Amount of drug added }(\mathrm{mg})} \times 100$

\section{Aerodynamic Assessment of Fine Particles Electron Microscopy}

The morphology of spray-dried NPs was characterized using scanning electron microscopy (SEM). Particles were placed onto an aluminum stage using conductive carbon tape. Samples were sputter-coated in the JFC-1600 Auto Fine CZZoater (JEOL Ltd., Tokyo, Japan) with gold-palladium for $120 \mathrm{~s}$ in a high vacuum evaporator.

Morphological examination of the atomizing solution was performed via transmission electron microscopy (TEM) (JEM-1400, JEOL, Japan). Briefly, a drop of atomizing solution was placed on a copper grid and stained with $1 \%$ $(w / v)$ of phosphotungstic acid and subsequently observed.

\section{In vitro Release}

The release profile was monitored using the dialysis method. Spray- or freeze-dried NP dispersion at a drug concentration of $50 \mu \mathrm{g} / \mathrm{mL}$ was introduced into a dialysis bag (Spectra/Por MWCO $=8000-14,000$ Da, USA) with $1 \mathrm{~mL}$, sealed with a dialysis clip. The bag was placed in $200 \mathrm{~mL}$ of water containing $2 \%$ sodium dodecyl sulfate (SDS). The entire system was centrifuged at $800 \mathrm{rpm}$ at $37 \pm 0.5^{\circ} \mathrm{C}$. The medium was replaced every $4 \mathrm{~h}$. At fixed time intervals, $0.2 \mathrm{~mL}$ of media was collected and replaced with an equal volume of fresh medium. The released DTX was discovered by HPLC.

\section{In vitro Inhalation Evaluation}

The dry powder sprayed by DTX-loaded NPs was introduced in a capsule. Each capsule contained approximately $30 \mathrm{mg}$ of dry powder. The aerodynamic assessment of drug-loaded NPs dry powder inhaler was evaluated using 
the Next Generation Pharmaceutical Impactor (NGI) (MSP Corporation, Minneapolis, USA), in line with the standard method listed in the British Pharmacopoeia 2007 Edition Appendix VII F. Apparatus E. The filled capsule was placed in the Cyclohaler dry powder inhaler at the end of the NGI inlet to puncture the capsule at $60 \mathrm{~L} / \mathrm{min}$. Powders were pumped down for $4 \mathrm{~s}$, which blew drug-loaded NP dry powder into the NGI, and pumping subsequently stopped. Thereafter, the NGI was opened and its elbows, cups, dry powder inhalers, and capsules rinsed with $10 \mathrm{~mL}$ of pure water. The obtained solution was transferred to a sample tube, and the DTX concentration in each sample solution was analyzed via HPLC.

Freeze-dried drug-loaded NPs were reconstituted with pure water to $10 \mu \mathrm{g} / \mathrm{mL}, 50 \mu \mathrm{g} / \mathrm{mL}$, and $100 \mu \mathrm{g} / \mathrm{mL}$, respectively, and the reconstituted solution was atomized into an inhalable droplet using a PARI TurboBOY N 085 inhalation system (PARI, Starnberg, Germany). The particle size of the spray droplet was determined using the Malvern Spraytec laser particle size analyzer (Malvern Instruments Ltd., UK) to evaluate the inhalability of drug-loaded NPs.

\section{Cellular Uptake of CLS-PEG NPs}

The A549 cell line was derived from human lung carcinoma. A549 cells were purchased commercially from the Cell Resource Center of Chinese Academy of Medical Sciences (Beijing, China), which is the National Infrastructure of Cell Line Resource of China. They were cultured in Minimum Essential medium (MEM) supplemented with $10 \%$ fetal bovine serum and $0.1 \mathrm{mM}$ nonessential amino acids (100 units $/ \mathrm{mL}$ of penicillin and 100 $\mu \mathrm{g} / \mathrm{mL}$ of streptomycin).

For imaging the cellular uptake of NPs, A549 cells were seeded a 6-well plate and cultured for $24 \mathrm{~h}$. Then, the medium was replaced with CLS-PEG NPs and incubated at $37^{\circ} \mathrm{C}$ for $2 \mathrm{~h}$. Subsequently, the cells were washed 3 times with PBS, fixed with $4 \%$ paraformaldehyde (did not interact with micelles) for $10 \mathrm{~min}$. After being washed 3 times with PBS to remove unbound paraformaldehyde, the cell nuclei counterstained with Hoechst33285 for $10 \mathrm{~min}$. Images were obtained using confocal laser scanning microscopy (Zeiss LSM 710, Göttingen, Germany).

\section{In vitro Anti-Proliferation Assay}

The anti-proliferative effect of DTX-loaded CLS-PEG NPs on cells was evaluated via the 3-(4,5-dimethylthiazol-2-yl)-2,5-diphenyltetrazolium bromide (MTT) assay. Firstly, A549 cells were seeded into a 96-well plate with a density of $5 \times 10^{3}$ cells/well. Blank samples were prepared by adding culture medium only. Cells were maintained overnight at $37^{\circ} \mathrm{C}$ in a humidified incubator containing $5 \% \mathrm{CO}_{2}$. Thereafter, A549 cells were incubated with different concentrations of NPs or free DTX for $24 \mathrm{~h}$ and $48 \mathrm{~h}$ at $37^{\circ} \mathrm{C}$. Cell culture medium $(180 \mu \mathrm{L})$ was removed and $20 \mu \mathrm{L}$ of MTT $(5 \mathrm{mg} / \mathrm{mL})$ was added after incubation. Plates were incubated for $4 \mathrm{~h}$. Thereafter, medium was removed from each well. Formazan crystals formed in wells with viable cells and these cells were resuspended in $200 \mu \mathrm{L}$ of DMSO. Samples were analyzed at an absorbance of $490 \mathrm{~nm}$ with a microplate reader (BioTek Instruments, Winooski, VT, USA). The assay was repeated three times with each experiment was composed of five independent replicates.

\section{Pharmacokinetic Detection HPLC Analysis}

The concentration of DTX was analyzed using the HPLC method, the Waters 2695 system equipped with a Waters 2487 dual-channel UV detector set at a wavelength of 230 $\mathrm{nm}$ and a C-18 column $(250 \mathrm{~mm} \times 4.6 \mathrm{~mm}, 5 \mu \mathrm{m}$, Phenomenex Inc., Torrance, CA, USA) with a flow rate of $1.0 \mathrm{~mL} / \mathrm{min}$ at $30^{\circ} \mathrm{C}$. Under these chromatographic conditions, the total run time was 12 min with the retention time of $9.290 \mathrm{~min}$ for DTX. The isocratic mobile phase composed of $\mathrm{ACN} / \mathrm{H}_{2} \mathrm{O}(55: 45 \mathrm{v} / \mathrm{v})$ was used for the analysis of DTX. There was not any interference for the in vivo samples. With a lower limit of quantification (LOQ) of $40 \mathrm{ng} / \mathrm{mL}$ and $10 \mathrm{ng} / \mathrm{g}$ in plasma and brain homogenates, respectively, and a lower limit of detection (LOD) of $20 \mathrm{ng} / \mathrm{mL}$ and $4 \mathrm{ng} / \mathrm{g}$ in plasma and brain homogenates, respectively, this method was sensitive for DTX in vivo. All validation data were within the required range.

\section{Preparation of Plasma and Tissue}

The extraction of DTX was conducted with the addition of $1 \mathrm{~mL}$ diethyl ether and mixed for $60 \mathrm{~s}$. This mixture was centrifuged for $5 \mathrm{~min}$ at $12,000 \mathrm{rpm}$, after which, the organic upper phase was transferred to a new tube and evaporated using a nitrogen stream. For sample loading, $200 \mu \mathrm{L}$ of acetonitrile (ACN) was added into the residue to reconstituted it and vortexed for $60 \mathrm{~s}$. After another centrifugation step for $5 \mathrm{~min}$ at $12,000 \mathrm{rpm}$, the supernatant was injected onto the HPLC system.

Lung samples were homogenized with saline in the ratio of 1:3 (wt/wt). Thereafter, $200 \mu \mathrm{L}$ lung homogenate 
was transferred to a tube by adding $1 \mathrm{~mL}$ diethyl ether and mixed for $60 \mathrm{~s}$. The mixture was centrifuged for $5 \mathrm{~min}$ at $12,000 \mathrm{rpm}$, after which the organic upper layer was transferred to a new tube and evaporated using a nitrogen stream. For sample loading, $200 \mu \mathrm{L}$ of ACN was added to the residue for reconstitution, followed by vortexing for $60 \mathrm{~s}$. Following an additional centrifugation step (5 $\mathrm{min}$ at $12,000 \mathrm{rpm}$ ), the supernatant was injected into the HPLC system.

Brain samples were homogenized with saline at a ratio of 1:3 (wt/wt). Thereafter, $2 \mathrm{~mL}$ brain homogenate was transferred to a tube to which $2 \mathrm{~mL}$ of sucrose solution was added $(26 \%, \mathrm{wt} / \mathrm{wt})$. The sample was then vortexed and centrifuged for $15 \mathrm{~min}$ at $6000 \mathrm{rpm}$, and the upper phase transferred to a new tube, to which $6 \mathrm{~mL}$ diethyl ether was added. The mixture was centrifuged for $5 \mathrm{~min}$ at $12,000 \mathrm{rpm}$, after which, the organic upper phase was transferred to a new tube and evaporated using a nitrogen stream. For sample loading, $200 \mu \mathrm{L}$ of $\mathrm{ACN}$ was added into the residue for reconstitution and vortexed for $60 \mathrm{~s}$. Following an additional centrifugation step ( $5 \mathrm{~min}$ at $12,000 \mathrm{rpm}$ ), the supernatant was injected into the HPLC system.

\section{Animals and Pharmacokinetic Study}

Male Wistar rats weighting 180-200 g were purchased from the Institute of Laboratory Animal Science, Chinese Academy of Medical Sciences (Beijing, China). All experiments were conducted according to the protocol (including animal ethics) approved by the Animal Care and Use Committee of the Chinese Academy of Medical Sciences, with the approval number SLXD-15041706. Rats were fed in a specific pathogen-free (SPF) animal house, with food and water freely available during experiments.

DTX was dissolved in 5\% (v/v) Tween 80 and $13 \%(\mathrm{v} / \mathrm{v})$ ethanol for the free drug solution, whereas, freeze-dried NP powders were dissolved in water. After at least $12 \mathrm{~h}$ of recovery from intubation of the right jugular vein, these rats were randomly assigned to five groups for pharmacokinetic investigation. Each group was given a dose of $10 \mathrm{mg} / \mathrm{kg}$ of either intravenous administration of free DTX solution (IV free drug group), intravenous administration of CLS-PEG NPs (IV CLS-PEG NPs group), intratracheal (IT) administration of free DTX solution (IT free drug group), freeze-dried powders (IT freeze-dried group) or spray-dried NP powders (IT spray-dried group). For the freeze-dried group, IT spray was loaded into a microsprayer (Model IA-1B, Penn-Century Inc., USA) and delivered into the trachea at a concentration of $1.0 \mathrm{~mL} / \mathrm{kg}$ via visual guidance. For the spray-dried group, spray-dried NPs powders were loaded into the dry powder insufflator (Model DP-4, Penn-CenturyInc., USA) and blown into the trachea via visual guidance. Following IT dosing, animals were held in an upright position for $1 \mathrm{~min}$ to ensure deposition, following removal of the delivery device.

Blood samples $(200 \mu \mathrm{L})$ were collected at $5,10,15,20$, $30,45,60 \mathrm{~min}$ and $120 \mathrm{~min}$ for the IV free drug group and 5, 15, 30, 45, $60 \mathrm{~min}, 2,4,6,8,10,12$ and $24 \mathrm{~h}$ for IV CLS-PEG NP and IT groups. Thereafter, $100 \mu \mathrm{L}$ of plasma was centrifuged at $5000 \mathrm{rpm}$ for $7 \mathrm{~min}$ at $0^{\circ} \mathrm{C}$. Plasma was stored at $-20^{\circ} \mathrm{C}$ prior to analysis.

\section{Tissue Distribution}

Rats were randomly divided into five groups and received either IV injection or IT administration as depicted in the previous section. Three rats at fixed time intervals $(0.25$, $0.5,1,2,4,8 \mathrm{~h}$ for IV injection and 1, 4, 8, 12, 24, $48 \mathrm{~h}$ for IT administration) were euthanized, perfused, and the lung and brain collected, washed, and weighed. Tissue samples were stored at $-20^{\circ} \mathrm{C}$ prior to analysis. All rats were administered with formulations at a DTX dose of $10.0 \mathrm{mg} / \mathrm{kg}$ by IT injection.

\section{In vivo Antitumor Evaluation}

To evaluate the efficacy of DTX-loaded CLS-PEG NPs for treating lung cancer in the airways, we established

Table I Dynamic Particle Size, Zeta Potentials and Encapsulation Parameters of Docetaxel (DTX)-Loaded Cholesterol-PEG CoModified Poly (n-Butyl) Cyanoacrylate Nanoparticles (CLS-PEG NPs)

\begin{tabular}{|l|l|l|l|l|}
\hline Parameters & Blank NPs & DTX CLS-PEG NPs & After Freeze-Drying & After Spray-Drying \\
\hline Particle size (nm) & $167.4 \pm 2.7$ & $182.3 \pm 3.2$ & $177.2 \pm 3.5$ & $189.4 \pm 2.7$ \\
Polydispersity index & $0.267 \pm 0.007$ & $0.217 \pm 0.011$ & $0.201 \pm 0.017$ & $0.274 \pm 0.031$ \\
Zeta potential (mV) & $-7.04 \pm 0.12$ & $-7.31 \pm 0.46$ & $-7.16 \pm 0.31$ & $-6.82 \pm 0.27$ \\
Drug loading (\%) & - & $1.87 \pm 0.12$ & $1.93 \pm 0.11$ & $1.75 \pm 0.08$ \\
Encapsulation efficiency (\%) & - & 96.4 & 97.2 & 94.8 \\
\hline
\end{tabular}

Note: Mean \pm SD, $\mathrm{n}=3$. 
an aggressive orthotopic mouse model of proximal lung cancer in inbred mice with intact host immunity. The model was established via intratracheal intubation of cancer cells into the tracheal and bronchial epithelium of lung airways, which is relevant to small cell lung cancer and squamous cell lung cancer. Briefly, female C57BL/6 mice (6-8 wk) were inoculated with $5 \times 105$ 3LL cells in $50 \mu \mathrm{L}$ of DMEM via intratracheal intubation. Subsequently, mice were randomly divided into five groups and received either IV injection or IT administration as depicted in the previous section ( $\mathrm{n}=6-10$ per group) at a dose of $10 \mathrm{mg} / \mathrm{kg}$ every three days for five times. The negative control group received no treatment. The body weights were recorded every 3 days. The mice were euthanized and the tumor in the lung collected, washed, and measured at 15 days after the last dose treatment of DTX.

\section{Statistical Analysis}

All data are represented as the mean \pm standard deviations (SD). Data were tested using a Student's two-tailed $t$-test or a factorial analysis of variance (ANOVA). Statistical significance was evaluated in advance to a probability level of 0.05 .

\section{Results \\ Characterization of DTX-Loaded \\ CLS-PEG NPs}

\section{Particle Size and Zeta Potential}

Particle size and zeta potential of NPs were measured by dynamic light scattering using a Zeta sizer Nano ZS. The
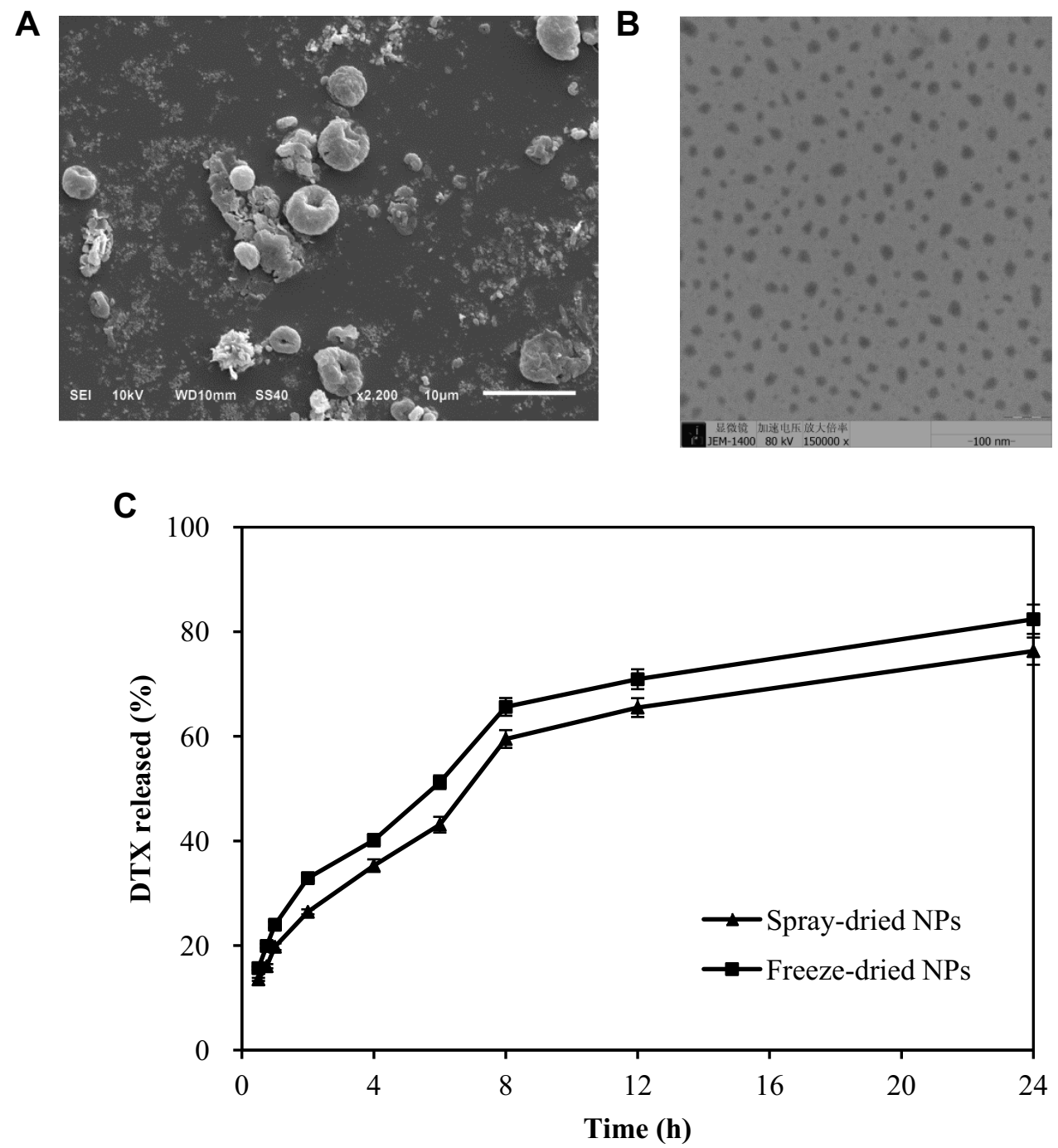

Figure I (A) Scanning electron microscopy (SEM) images of spray-dried particles containing cholesterol-PEG co-modified poly (n-butyl) cyanoacrylate nanoparticles (CLSPEG NPs) loaded with docetaxel (DTX). (B) Transmission electron microscopy (TEM) images of atomizing solution containing DTX-load CLS-PEG NPs. (C) The in vitro release profiles of spray-dried and freeze-dried CLS-PEG NPs loaded with DTX (mean \pm SD, $n=3$ ). 
particle size of DTX-loaded CLS-PEG NPs was determined to be $182.3 \pm 3.2 \mathrm{~nm}$ with a comparatively narrow size distribution that showed a polydispersity index (PDI) value of $0.217 \pm 0.011$ (Table 1). Zeta potential is an important index to characterize the stability of colloidal dispersion system. The zeta potential of DTX-loaded CLSPEG NPs was $-7.31 \pm 0.46 \mathrm{mV}$, suggesting that it might prevent aggregation and improve dispersion stability of NPs. The spray-drying and freeze-drying processes affected neither the particle size nor the zeta potential of the NPs, as indicated in Table 1.

\section{Drug Loading and Encapsulation Efficiency}

The concentration of DTX and the encapsulation efficiency were determined by HPLC at $230 \mathrm{~nm}$. DTX-loaded CLSPEG NPs showed a drug loading of $(1.87 \pm 0.12) \%$ and an encapsulation efficiency of $96.4 \%$ (Table 1), indicating that CLS-PEG NPs well-wrapped DTX thus might avoid leakage of encapsulated DTX. The spray-drying and freezedrying processes showed no obvious influence on the drug loading and encapsulation efficiency of DTX-loaded CLSPEG NPs (Table 1).

\section{Aerodynamic Assessment of Fine Particles \\ Electron Microscopy}

The CLS-PEG NPs were spray-dried to yield inhalable microparticles. The morphology of these particles was assessed using SEM. As shown in Figure 1A, the morphology of spray-dried particles is smooth to moderately dimpled and raisin-like.

The results from TEM showed that the atomizing solution has good dispersion in vitro (Figure 1B). The nebulization process did not influence the transport behavior of NPs within the deep lung tissue.

\section{In vitro Release}

The release profile of DTX is shown in Figure 1C. When encapsulated by CLS-PEG NPs, the spray-or freeze-dried NPs were released, in a sustained manner, over $24 \mathrm{~h}$. The release of DTX from NPs after $24 \mathrm{~h}$ was $76.3 \%$ for spraydried NPs and $82.4 \%$ for freeze-dried NPs. These in vitro release data suggest that CLS-PEG NPs are potentially useful to control the release of DTX and that the significantly sustained release is likely attributed to the slower diffusion of DTX from the NPs rather than the penetration of drug molecules across the dialysis membrane. These data also suggest that DTX was slowly released from spray- or freeze-dried NPs.

\section{In vitro Inhalation Evaluation}

The aerodynamic characteristics for spray-dried particles in vitro are shown in Table 2, and its deposition distribution is shown in Figure 2. The Mass Median Aerodynamic Diameter (MMAD) for spray-dried particles was $4.20 \pm 0.12$ $\mu \mathrm{m}$ with a Geometric Standard Deviation (GSD) of $4.44 \pm$ 0.31 (Table 2). The fine particle fractions (FPF) $(<5 \mu \mathrm{m})$ were found to be $59.44 \pm 2.36 \%$. The above results indicate that spray-dried particles for CLS-PEG NPs, prepared by using $10 \%$ leucine as an excipient, had better inhalability.

Here, we used laser diffraction to analyze particle size and particle size distribution of the droplets and to assess inhalability of the aerosol. D50 and span parameters were used to evaluate particle size and particle size distribution of droplets of different concentrations of drug-loaded CLSPEG NPs (Table 3, Figure 2B, C and D). The D50 values droplets with concentrations at $10 \mu \mathrm{g} / \mathrm{mL}, 50 \mu \mathrm{g} / \mathrm{mL}$, and $100 \mu \mathrm{g} / \mathrm{mL}$ of drug-loaded CLS-PEG NPs after spray were $3.27 \pm 0.08 \mu \mathrm{m}, 3.36 \pm 0.04 \mu \mathrm{m}$, and $3.35 \pm 0.06 \mu \mathrm{m}$, respectively, and the span values were $1.25 \pm 0.03,1.18 \pm$ $0.02,1.37 \pm 0.02$, respectively. These data suggested that droplets after spray with different concentrations of drugloaded CLS-PEG NPs exhibited similar geometric size distribution, and all three aerosols have excellent dispersion and narrow particle size distribution. The percentage of drug inhaled droplets, at concentrations of $10 \mu \mathrm{g} / \mathrm{mL}$, $50 \mu \mathrm{g} / \mathrm{mL}$, and $100 \mu \mathrm{g} / \mathrm{mL}$ drug-loaded CLS-PEG NPs after spray were $88.23 \pm 1.45 \%, 87.11 \pm 1.75 \%$, and 86.00

Table 2 The Aerosol Performance and Aerodynamic Properties of Spray-Dried Powder for DTX-Load CLS-PEG NPs

\begin{tabular}{|c|c|}
\hline Leucine Content & $10 \%$ \\
\hline $\mathrm{TD}(\mu \mathrm{g})^{\mathrm{a}}$ & $493.48 \pm 18.99$ \\
\hline $\operatorname{ED}(\mu g)^{b}$ & $451.57 \pm 17.32$ \\
\hline ED (\%) & $91.50 \pm 1.19$ \\
\hline $\operatorname{MMAD}(\mu \mathrm{m})^{c}$ & $4.20 \pm 0.12$ \\
\hline$G_{S D}^{d}$ & $4.44 \pm 0.31$ \\
\hline FPD $(\mu g)^{\mathrm{e}}$ & $268.42 \pm 10.83$ \\
\hline $\operatorname{FPF}_{\mathrm{TD}}(\%)^{\mathrm{f}}$ & $54.39 \pm 2.30$ \\
\hline $\mathrm{FPF}_{\mathrm{ED}}(\%)$ & $59.44 \pm 2.36$ \\
\hline
\end{tabular}

Notes: Mean $\pm S D, n=3$. ${ }^{a} T D$ : total dose. ${ }^{b} E D$ : emitted dose. ${ }^{C M M A D:}$ mass median aerodynamic diameter was the diameter at the $50 \%$ cumulative percentage whilst. ${ }^{\mathrm{d}} \mathrm{GSD}$ : the geometric standard deviation was defined as the ratio of the diameter at the $84.1 \%$ cumulative percentage to $50 \%$. ${ }^{\mathrm{e}} \mathrm{FPD}$ : fine particle dose was calculated as the recovered dose of active ingredients exhibiting an aerodynamic diameter of $<5 \mu \mathrm{m}$. ${ }^{\mathrm{f}} \mathrm{FPF}$ : fine particle fractions were defined as the fine particle dose divided by the whole dose of drug found in the impactor (including the throat). 
$\pm 2.06 \%$, respectively. These data indicate that droplets after spray at different concentrations of drug-loaded CLSPEG NPs have better lung inhalability.

\section{Cellular Uptake of CLS-PEG NPs}

Confocal laser scanning microscopic images of A549 cells post-incubation are shown in Figure 3. The confocal microscopy allowed visualization of the intracellular distribution of NPs. After $2 \mathrm{~h}$ incubation with DTX-loaded CLS-PEG NPs, cells showed fluorescence attributable to Nile red loaded in the NPs in the cytoplasm rather than on the surface of cell membranes, confirming the internalization of NPs.

\section{In vitro Anti-Proliferation Effect}

In our previous studies, ${ }^{22}$ non-cytotoxic empty nanoparticles were developed (cell viabilities $>95 \%$ ). Therefore, we concluded that CLS-PEG NPs are a safe and biocompatible vector. The anti-proliferative activity was measured using the MTT-assay in A549 human lung carcinoma cell line. The results showed that DTX inhibited the

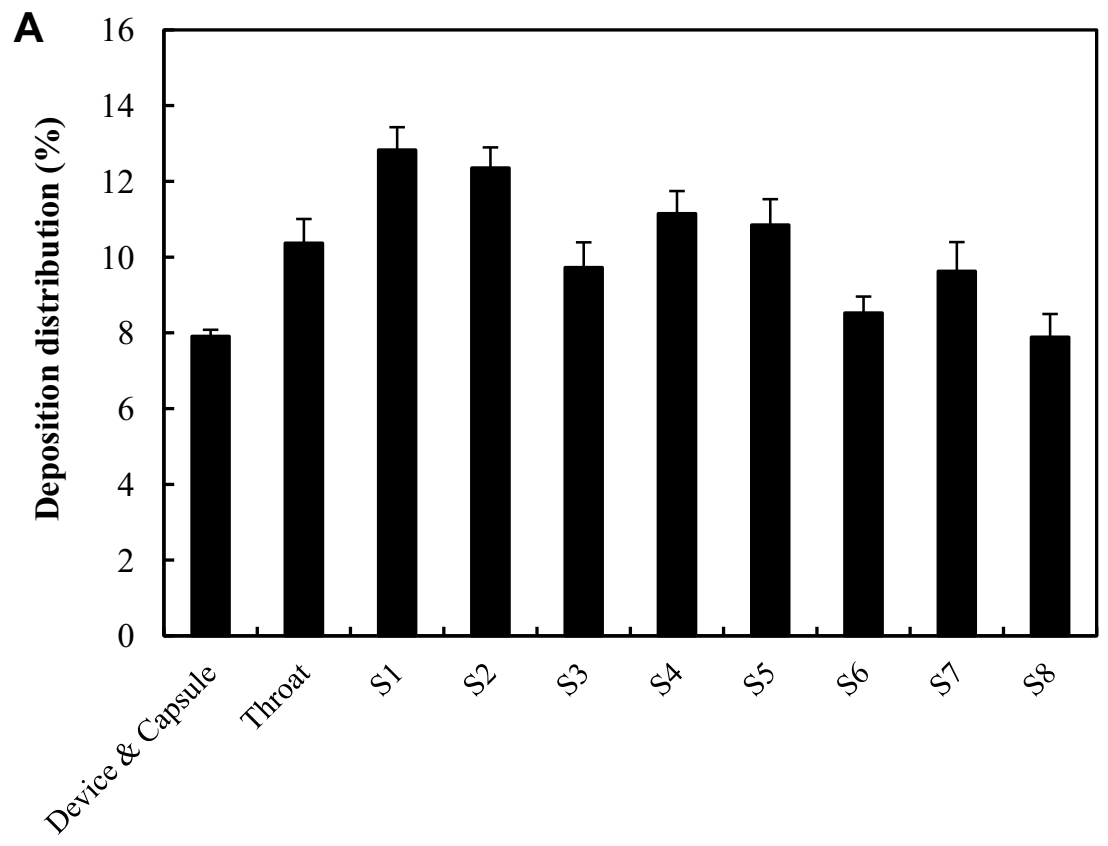

S1-S7: Stage 1-7 collector

S8: Micro-orifice collector (MOC)

B

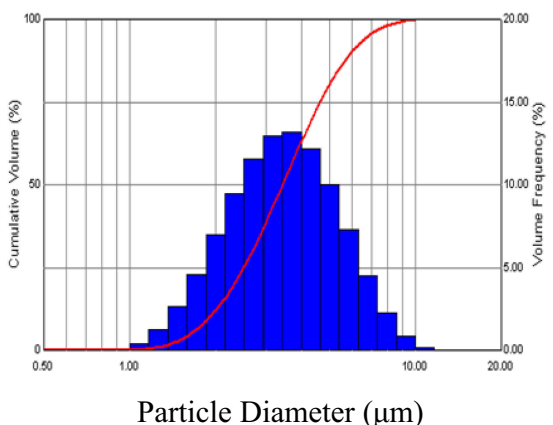

Particle Diameter $(\mu \mathrm{m})$
C

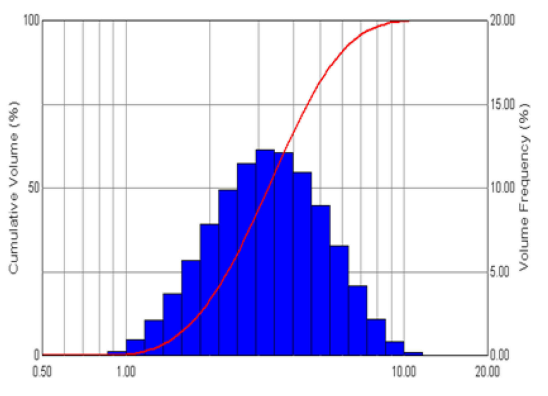

Particle Diameter $(\mu \mathrm{m})$

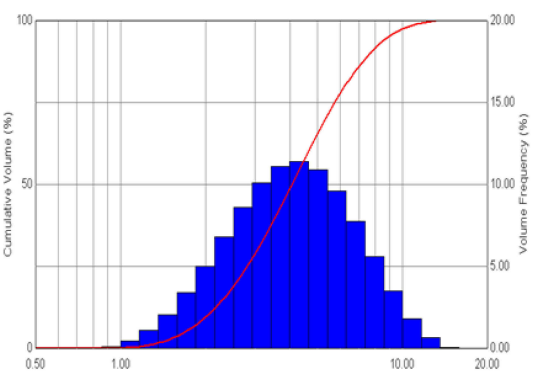

Particle Diameter $(\mu \mathrm{m})$

Figure 2 (A) The deposition distribution of spray-dried powders for DTX-load CLS-PEG NPs (mean \pm SD, $n=3$ ). Size and size distribution of aerosol droplets generated from (B) $10 \mu \mathrm{g} / \mathrm{mL}$, (C) $20 \mu \mathrm{g} / \mathrm{mL}$, (D) $100 \mu \mathrm{g} / \mathrm{mL}$ DTX-load CLS-PEG NPs using air-jet nebulizers. 
Table 3 Size, Size Distribution and Inhalable Aerosol Droplets Generated from Different Concentrations of DTX-Loaded CLSPEG NPs Using Air-Jet Nebulizers

\begin{tabular}{|l|l|l|l|}
\hline Concentration & $\mathbf{1 0} \boldsymbol{\mu g} / \mathbf{m L}$ & $\mathbf{5 0} \boldsymbol{\mu g} / \mathbf{m L}$ & $100 \mu \mathbf{g} / \mathbf{m L}$ \\
\hline$D_{50}(\mu \mathrm{m})$ & $3.27 \pm 0.08$ & $3.36 \pm 0.04$ & $3.35 \pm 0.06$ \\
Span & $1.25 \pm 0.03$ & $1.18 \pm 0.02$ & $1.37 \pm 0.02$ \\
Inhalability (\%) & $88.23 \pm 1.45$ & $87.11 \pm 1.75$ & $86.00 \pm 2.06$ \\
\hline
\end{tabular}

Note: Mean $\pm S D, n=3$.

proliferation of A549 cells in a concentration-dependent manner within a 24- and 48-h time frame. Moreover, CLSPEG NPs increased DTX inhibition on the proliferation of A549 cells in all groups (Figure 4). The half maximal inhibitory concentration (IC50) for inhibiting A549 cell proliferation was calculated. The IC50 value of DTXloaded CLS-PEG NPs $(0.234 \mathrm{nmol} / \mathrm{mL})$ was much lower than that of free DTX solution $(7.372 \mathrm{nmol} / \mathrm{mL})$ in $24 \mathrm{~h}$ treatment, and the IC50 value of DTX-loaded CLSPEG NPs $(0.058 \mathrm{nmol} / \mathrm{mL})$ was lower compared with free DTX solution $(1.317 \mathrm{nmol} / \mathrm{mL})$ in $48 \mathrm{~h}$ treatment. These results indicated that DTX-loaded CLS-PEG NPs had a stronger anti-proliferation effect on carcinoma cells than free DTX solution in vitro.

\section{Pharmacokinetic Study}

The plasma concentration-time curves for DTX after IV or IT administration is shown in Figure 5, and the pharmacokinetic parameters are listed in Table 4. As shown in Figure 5, CLS-PEG NPs led to relatively high plasma levels at $6 \mathrm{~h}$, but was undetectable after $2 \mathrm{~h}$ of intravenous administration of the free drug. Following IT administration, the plasma concentration of DTX decreased below the lower limit of detection (LLOD) within $6 \mathrm{~h}$, whereas CLS-PEG NPs prolonged the plasma concentration of DTX for more than $24 \mathrm{~h}$ for freeze-dried powders or spray-dried powders. Furthermore, freeze-dried powders were found to increase the $t_{1 / 2}$ and AUC 2.3 and 6.5 fold compared to the free drug after IT administration, and spray-dried powders were found to increase the $t_{1 / 2}$ and AUC 3.4 and 8.8 fold (Table 4). Although the Cmax of plasma DTX increased with freezedried CLS-PEG NPs, there was no significant difference in the AUC between freeze-dried powders and spray-dried powders $(\mathrm{p}>0.05)$. Pharmacokinetic data suggested that the CLS-PEG NPs provided, not only better stabilization but also a more sustained release in vivo.

\section{Tissue Distribution}

The details of DTX after IV or IT administration are shown in Figure 6, and the $\mathrm{AUC}_{0-24 \mathrm{~h}}$ values are shown in Table 5. When compared with IV administration, IT administration resulted in evidently higher DTX concentrations in the lung. When compared with the IT-free drug, freeze-dried and spray-dried powder CLS-PEG NPs also had an appreciably higher AUC in the lung after IT administration, with an approximate 3.4 and 4.3 fold increase. The high DTX content in the lung after IT administration could make NP a potential means for lung cancer metastasis.

For the free solution of DTX, only a small amount of the drug could be delivered to the brain, and was undetectable at all included time points after IV or IT administration (Figure 6A). Addition of DTX to CLS-PEG NPs showed a higher and more sustained distribution of DTX
Nile red

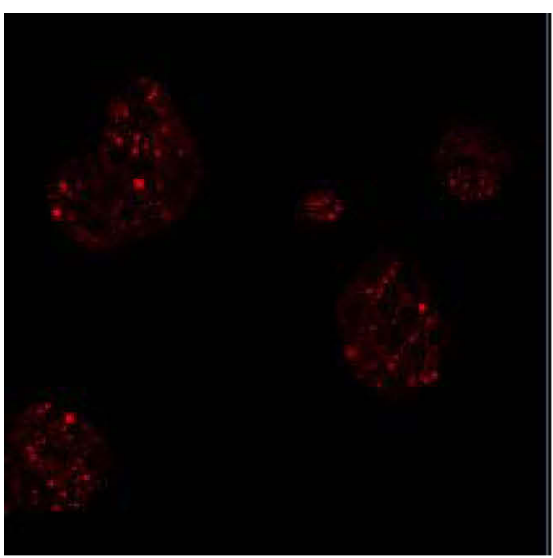

Hoechst33258

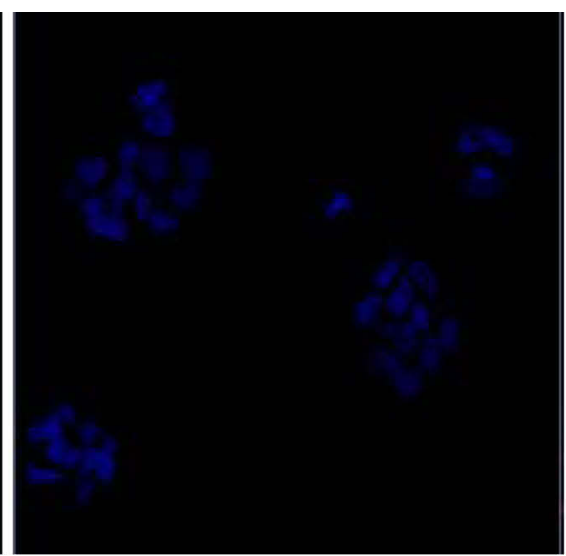

Merge

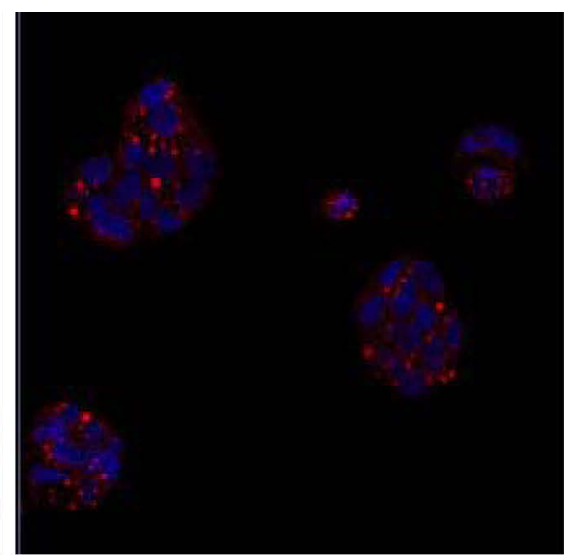

Figure 3 Cellular uptake of DTX-loaded CLS-PEG NPs. A549 cells were incubated with CLS-PEG NPs at $37^{\circ} \mathrm{C}$ for $2 \mathrm{~h}$. The confocal laser scanning microscopy was used to observe the distribution of Nile red loaded in the NPs, and the cell nuclei counterstained with Hoechst33285. 

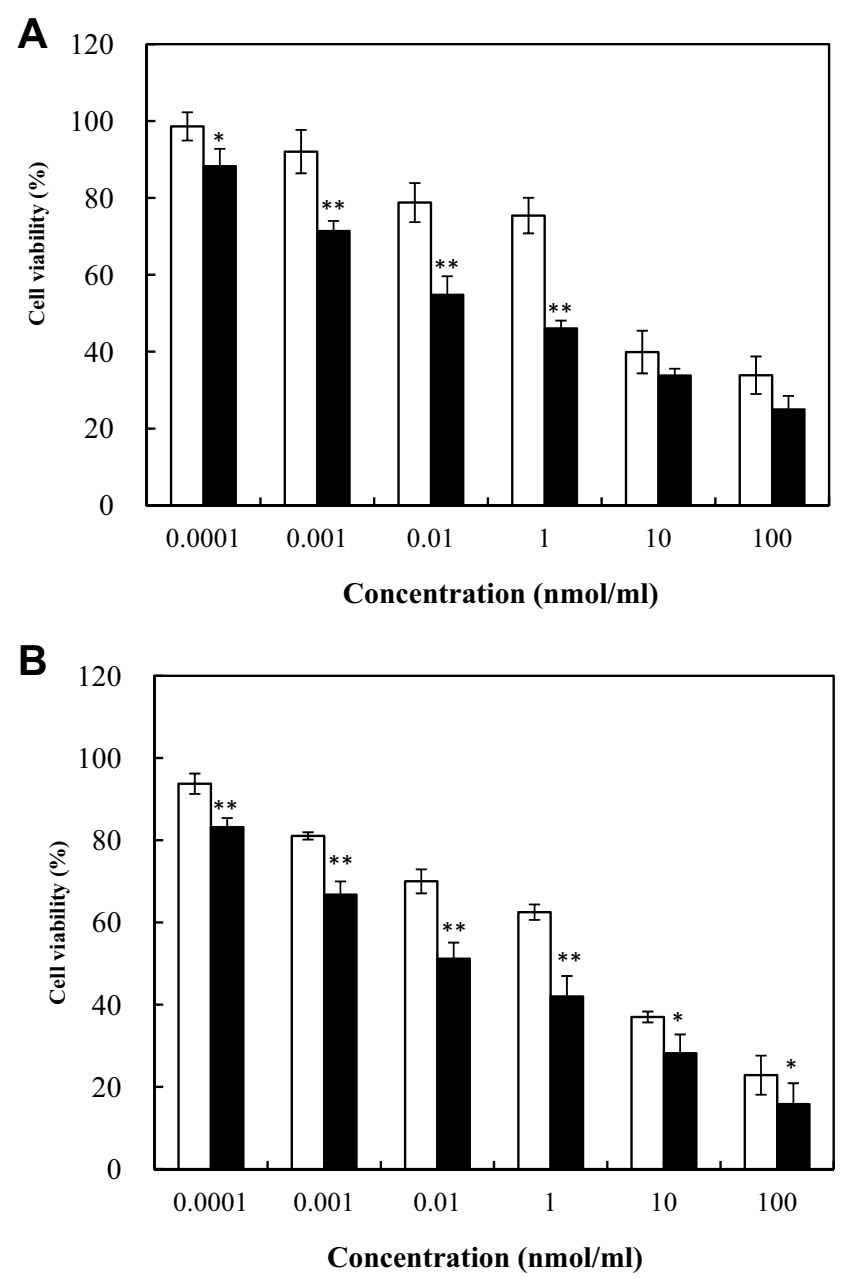

Figure 4 Anti-proliferation assay of free DTX ( $\square$ ) and DTX-loaded CLS-PEG NPs (घ) at different concentrations in A549 human lung carcinoma cells after (A) 24 $\mathrm{h}$ and $(\mathrm{B}) 48 \mathrm{~h}$ treatment. Mean $\pm \mathrm{SD}, \mathrm{n}=5$. $* \mathrm{P}<0.05$, $* * \mathrm{P}<0.0 \mathrm{l}$ versus the free DTX group.

in the brain, relative to the free solution of DTX after IV or IT administration (Figure 6A). Additionally, IT CLS-PEG NPs (both freeze-dried and spray-dried powders) resulted in enhanced AUC values and $t_{1 / 2}$ of DTX in the brain compared with IV CLS-PEG NPs (Table 5).

The in vivo time-dependent distribution of free DTX solution, freeze-dried powders or spray-dried powders of CLSPEG NPs loaded with DTX in the brain, lung, liver and kidney of mice during 1, 4 and $12 \mathrm{~h}$ after IT administration was also evaluated by multispectral optoacoustic tomography (MSOT) (Figure S1). These data suggest that IT CLS-PEG NPs can pass through the blood-brain-barrier, and inhalation may be used as a non-invasive means for brain targeting.

\section{In vivo Antitumor Effect}

To evaluate the efficacy of CLS-PEG NPs for treating lung cancer in the airways, we also established an aggressive orthotopic mouse model of proximal lung cancer in inbred mice with intact host immunity. During the efficacy evaluation, the variations in the body weights of the mice as a function of time (Figure 7A) were utilized as an indicator. The results showed that the body weights of the mice in the negative control group and DTX treated groups existed no significant differences among the groups (ANOVA, $\mathrm{P}>0.05$ ). The efficacy results (Figure 7B) showed that on day-15 after the last dose treatment of DTX, the tumor volume was decreased in the mice treated with DTX-loaded CLS-PEG NPs compared with the free DTX group after IV injection and IT administration, and the antitumor effect of IT administration was better than that of IV injection, whilst the groups treated with IV free DTX led to only insignificant inhibition of tumor growth (ANOVA, $\mathrm{P}>0.05$ ). The reason for enhanced efficacy of the pulmonary delivered NPs formulation might be attributed to the improved local availability of DTX to tumors in the lung as a result of stabilization and sustained release conferred by the entrapment in the NPs.

\section{Discussion}

According to previous studies, NPs solution can prevent mucociliary clearance of lung in vivo, and increase the uptake of NPs by epithelial and cancer cells simultaneously. ${ }^{23-25}$ However, NPs are easily exhaled through the respiratory tract, which is a major disadvantage for pulmonary administration of NPs. ${ }^{26}$

To enable smooth inhalation and deposition of drugloaded NPs into the lungs, it is necessary to prepare a formulation which has good inhalability and does not change the physicochemical properties and sustained release characteristics of drug-loaded NPs. Particle size and zeta potential results also indicated that spray-drying and freezedrying processes did not change the physicochemical properties of NPs after re-dispersion. According to previous studies, ${ }^{27}$ there is no notable influence on the MMAD of the particles for NPs. Therefore, after inhalation and deposition into the lungs in the form of aggregated particles, NPs could re-dissolve into their nanometer size in the aqueous surroundings on the lung epithelium, and bypass the airblood barrier and distribute to the extra-pulmonary organs.

In principle, the aerodynamic diameter of the inhalable formulation should be $<5 \mu \mathrm{m} .{ }^{25}$ The particles will be deposited in the upper respiratory tract when its aerodynamic diameter is larger than $5 \mu \mathrm{m}$. When the aerodynamic particle size is between 1 and $5 \mu \mathrm{m}$, gravity sedimentation plays a major role, and the particles will be deposited in the smaller respiratory tract and the thin bronchus. In addition, 

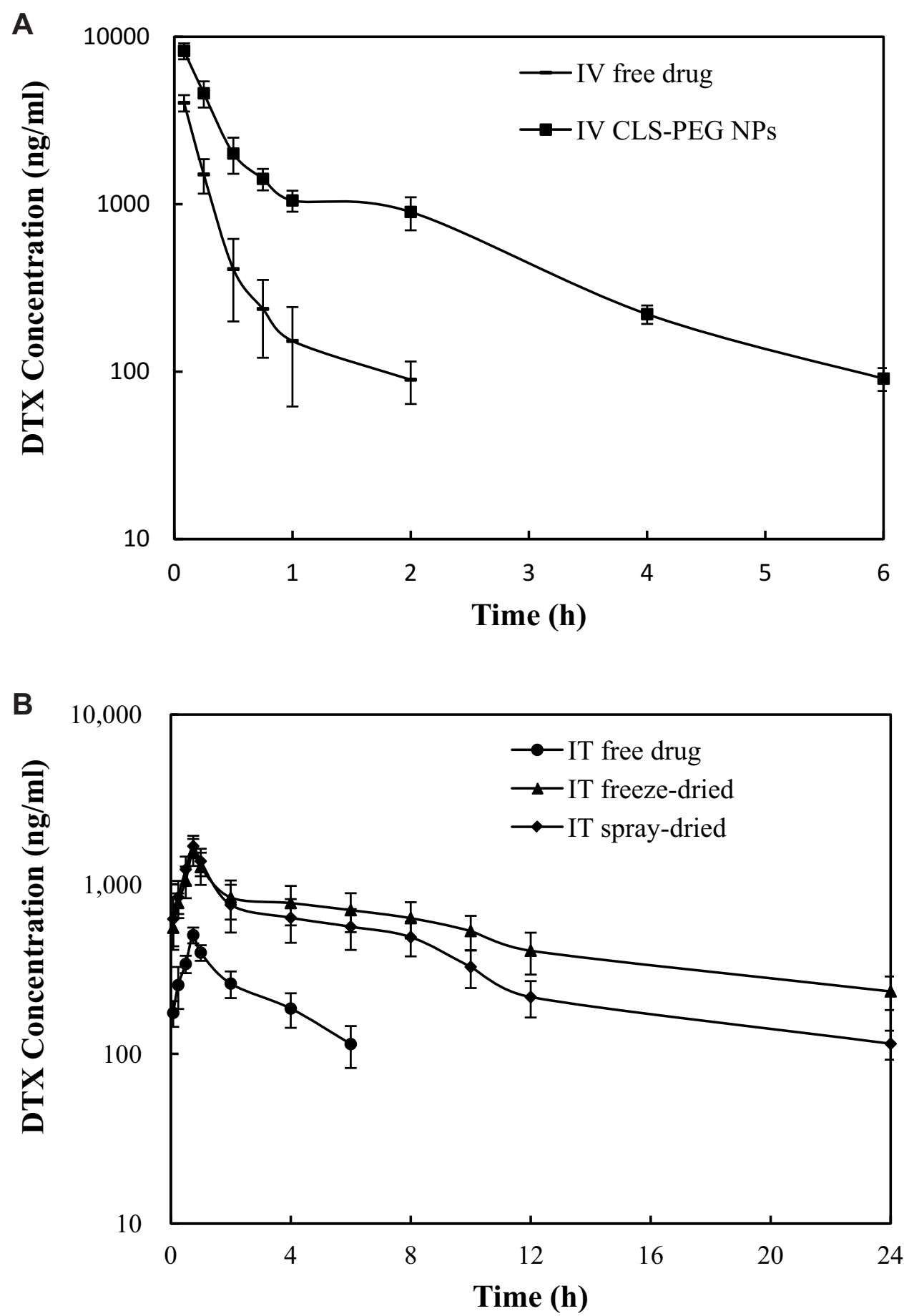

Figure 5 (A) Plasma concentrations of DTX versus time after intravenous (IV) administration of free DTX solution or DTX-loaded CLS-PEG NPs to rats at a dose of $10 \mathrm{mg} / \mathrm{kg}$ (mean $\pm S D, n=6$ ). (B) Plasma concentrations of DTX versus time after intratracheal (IT) administration of free DTX solution, freeze-dried or spray-dried CLSPEG NPs loaded with DTX to rats at a dose of $10 \mathrm{mg} / \mathrm{kg}($ mean $\pm S D, n=6)$.

the anatomy and pathophysiology of the patient's respiratory tract, the patients' age, mode of inhalation through the inhaler, and other conditions in lung cancer patients may affect the deposition of aerosolized inhalation in the lung.
However, these factors are often not within our control and is momentarily not a part of our research work. Therefore, we use particles below $5 \mu \mathrm{m}$ in diameter as the inhalable particle, and calculated the proportion of inhalable drugs 
Table 4 Pharmacokinetic Parameters of DTX After Intratracheal (IT) or Intravenous (IV) Administration of Free DTX Solution or DTX-Loaded CLS-PEG NPs to Rats at a Dose of $10 \mathrm{mg} / \mathrm{kg}$

\begin{tabular}{|l|l|l|l|l|l|}
\hline Parameters & Free Drug (IV) & CLS-PEG-NPs (IV) & Free Drug (IT) & Freeze-Dried (IT) & Spray-Dried (IT) \\
\hline $\mathrm{C}_{0}(\mathrm{ng} / \mathrm{mL})$ & $6589.7 \pm 755.1$ & $11018.4 \pm 2294.2$ & - & - & - \\
$\mathrm{Cmax}(\mathrm{ng} / \mathrm{mL})$ & - & - & $501.4 \pm 130.6$ & $1676.3 \pm 345.4$ & $1564.6 \pm 382.7$ \\
$\mathrm{t}_{1 / 2}, \lambda \mathrm{z}(\mathrm{min})$ & $58.7 \pm 6.6$ & $79.0 \pm 9.7$ & $202.6 \pm 23.4^{* *}$ & $462.4 \pm 75.6^{* *}$ & $684.9 \pm 108.9^{* * *}$ \\
$\mathrm{AUC}_{0-\mathrm{t}}(\mu \mathrm{g} \cdot \mathrm{min} / \mathrm{mL})$ & $83.6 \pm 17.8$ & $350.4 \pm 47.0^{* *}$ & $84.3 \pm 12.1$ & $550.8 \pm 132.9 * *$ & $746.4 \pm 125.4^{* *}$ \\
$\mathrm{AUC} \mathrm{C}_{0-\infty}(\mu \mathrm{g} \cdot \mathrm{min} / \mathrm{mL})$ & $91.2 \pm 20.7$ & $360.8 \pm 61.7^{* *}$ & $117.7 \pm 16.7$ & $627.4 \pm 144.7^{* *}$ & $977.1 \pm 179.2^{* *}$ \\
$\mathrm{~V}_{\mathrm{d}}, \lambda \mathrm{z}(\mathrm{L})$ & $9.3 \pm 1.0$ & $3.2 \pm 0.3^{* *}$ & $24.8 \pm 4.5^{* *}$ & $10.6 \pm 2.3$ & $10.1 \pm 1.5$ \\
$\mathrm{CL}(\mathrm{mL} / \mathrm{min})$ & $109.6 \pm 6.6$ & $27.7 \pm 2.5^{* *}$ & $85.0 \pm 13.0$ & $15.9 \pm 3.6^{* *}$ & $10.2 \pm 2.3^{* *}$ \\
$\mathrm{~F}(\%)$ & - & 395.6 & 129.0 & 687.9 & 1071.4 \\
\hline
\end{tabular}

Notes: Mean $\pm S D, n=6$. $* * P<0.01$, compared to free drug (IV). ${ }^{*} p<0.05$, compared to freeze-dried (IT).

based on the particle distribution. The aerodynamics results indicated that both the atomizing solution and dry powder inhalation for CLS-PEG NPs have the potential to be used as a novel treatment for lung cancer via pulmonary delivery.
The freeze-dried powders have the advantages of accurate measurement, uniform drug distribution, fast onset, and easy to use. But it also has limitations, such as the environmental pollution that may be caused by
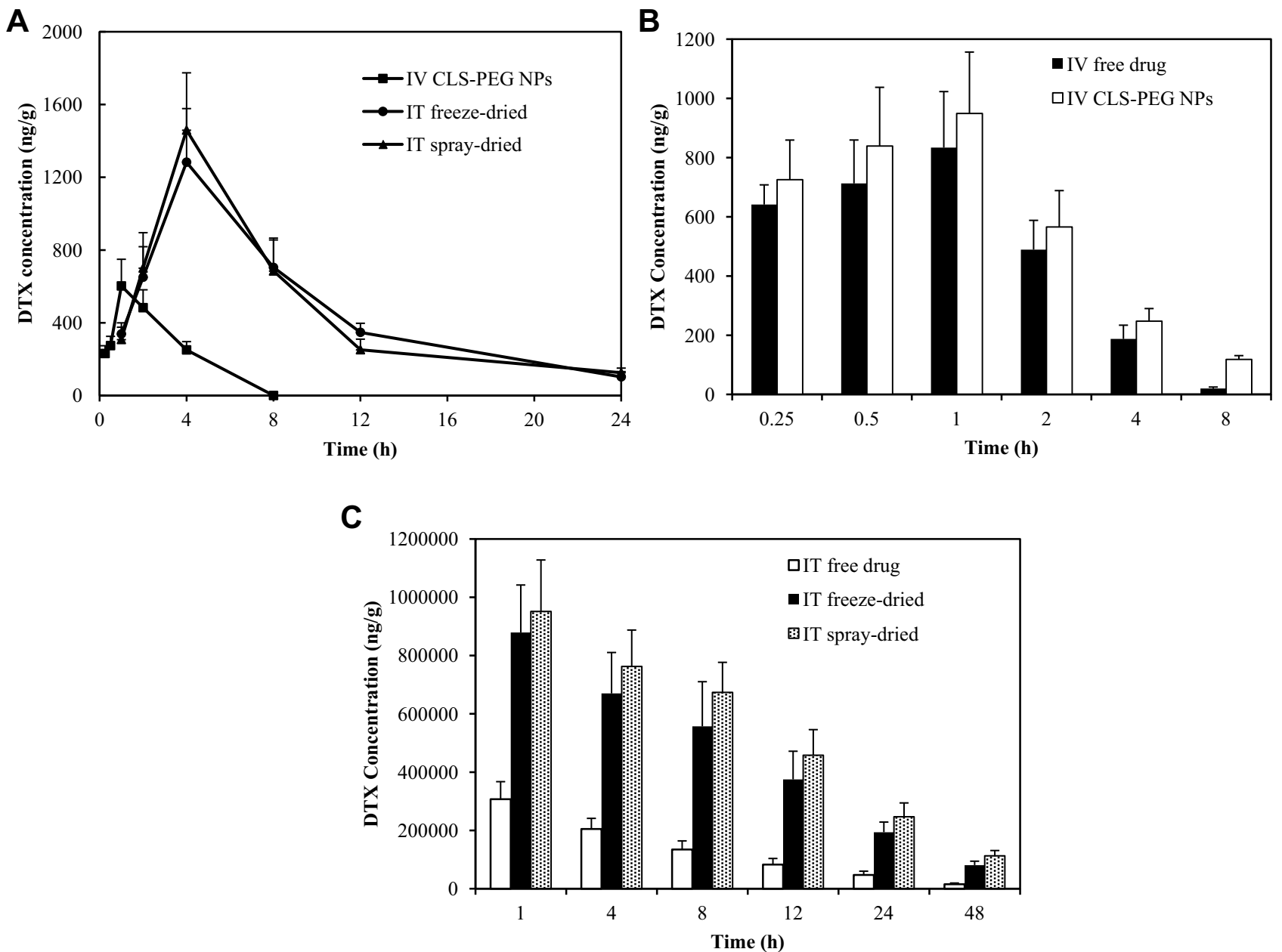

Figure 6 (A) Mean DTX concentration-time profiles in the brain after intratracheal (IT) or intravenous (IV) administration of free DTX solution or DTX-loaded CLS-PEG NPs to rats at a dose of $10 \mathrm{mg} / \mathrm{kg}$ (mean $\pm \mathrm{SD}, \mathrm{n}=3$ ). (B) Mean DTX concentration-time profiles in the lung after intravenous (IV) administration of free DTX solution or DTX-loaded-CLS-PEG NPs to rats at a dose of $10 \mathrm{mg} / \mathrm{kg}$ (mean $\pm \mathrm{SD}, \mathrm{n}=3$ ). (C) Mean DTX concentration-time profiles in the lung after intratracheal (IT) administration of free DTX solution, freeze-dried or spray-dried CLS-PEG NPs loaded with DTX to rats at a dose of $10 \mathrm{mg} / \mathrm{kg}(\mathrm{mean} \pm \mathrm{SD}, \mathrm{n}=3)$. 
Table 5 Pharmacokinetic Parameters of DTX in the Tissue and Drug Targeting Index (DTI) to Brain in Five Groups of Rats After Intratracheal (IT) or Intravenous (IV) Administration of Free DTX Solution or DTX-Loaded CLS-PEG NPs to Rats at a Dose of I0 mg/kg

\begin{tabular}{|c|c|c|c|}
\hline Tissue & $A U C_{0-t}(\mu \mathrm{g} \mathrm{min} / \mathrm{mL})$ & $C_{\max }(\mathbf{n g} / g)$ & $\mathbf{T}_{\max }(\mathbf{h})$ \\
\hline \multicolumn{4}{|l|}{ Brain } \\
\hline IV CLS-PEG NPs & $207.3 \pm 26.4$ & $602.4 \pm 146.5$ & $2.2 \pm 0.4$ \\
\hline IT freeze-dried & $698.4 \pm 109.9^{\& \&}$ & $1082.8 \pm 294.5^{2 \&}$ & $5.8 \pm 1.2^{\& \&}$ \\
\hline IT spray-dried & $689.7 \pm 124.6^{8 \&}$ & $1159.3 \pm 214.6^{8 \&}$ & $6.3 \pm 1.1^{\& \&}$ \\
\hline \multicolumn{4}{|l|}{ Lung } \\
\hline IV free drug & $145.6 \pm 21.8$ & $833.8 \pm 189.3$ & $1.3 \pm 0.2$ \\
\hline IV CLS-PEG NPs & $206.7 \pm 36.7$ & $949.3 \pm 207.4$ & $2.4 \pm 0.3^{* *}$ \\
\hline IT free drug & $28 \mid 333.0 \pm 48692.9^{* *}$ & $307298.8 \pm 59821.2^{* *}$ & $15.6 \pm 1.9 * *$ \\
\hline IT freeze-dried & $973042.8 \pm 181852.3 * * \#$ & $878966.8 \pm 162885.0 * * \#$ & $16.6 \pm 3.5 * * \#$ \\
\hline IT spray-dried & $|2| 1742.1 \pm 225784.3^{* * \#}$ & $951021.2 \pm 176682.2^{* * \#}$ & $18.2 \pm 3.1 * * \# \#$ \\
\hline
\end{tabular}

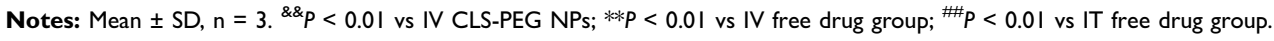

propellants; the delivered drug dose is relatively small; and many patients, especially children, cannot rationally use drugs because they cannot coordinate their own breathing and inhalation device release. The spray-dried powders have the advantages of no propellant, large drug loading, high patient-controlled inhalation safety. At the same time, the stability of the dry powders is good at room temperature, and the efficiency of inhalation is high, which is not easy to be contaminated by microorganisms. IT delivered CLS-PEG NPs led to sustained plasma levels for up to $24 \mathrm{~h}$, but when compared to CLS-PEG NPs administered intravenous, significantly lower $(\mathrm{P}<0.01)$ plasma levels were observed for the initial $2 \mathrm{~h}$. These findings are similar to those reported by Gill et al, who investigated paclitaxel loaded PEG5000-DSPE micelles. ${ }^{28}$ The AUC of freezedried powders or spray-dried powders was significantly higher after IT administration, but there was no significant difference in the AUC between freeze-dried powders and spray-dried powders $(p>0.05)$. The systemic bioavailability of inhaled drugs depends on competing results between absorption and clearance. Lung retention of the inhaled drug is also dictated by drug deposition and clearance mechanisms within the lung. Here, the CLS-PEG NPs were processed to spray-dried or freeze-dried NPs powders. Therefore, IT NPs always led to significantly higher lung concentrations of DTX than IV administration; however, the different inhalers appeared to not result in different lung retention. This study hypothesized that spray-dried powders may be used as a means to prolong airway retention and sustain pulmonary release partially to freeze-dried powders due to limited dissolution rate absorption and the presence of mucoadhesive excipients of leucine. However, different inhalers appeared to not result in different pulmonary absorption times or bioavailability, only the half-life of the DTX in the spray-dried powders was longer than the freeze-dried powders (Tables 4 and 5). This might be attributed to the elevated solubility of CLS-PEG NPs because although DTX is extremely insoluble in water, its solubility increases greatly after entrapment into CLS-PEG NPs.

Moreover, approximately $10 \%$ of lung cancer patients are first metastasized with brain metastases and 30-50\% metastasized to the brain during the way of the disease, ${ }^{24}$ and the prognosis of lung cancer with brain metastasis is extremely poor, with a median survival rate under 6 months, even after palliative radio and/or chemotherapy. ${ }^{25}$ The growing incidence of brain metastasis (BM) was regarded as the aging population and better control of systemic diseases. ${ }^{29,30,31}$ At present, brain radiation treatment is the criterion for most patients with brain metastases from lung cancer. Moreover, patients with a single metastasis may receive surgical treatment or stereotactic radiosurgery. ${ }^{32,33}$ The brain may be described as a prior site of proliferation for a great amount of the commodious treatment could not go through the BBB at present, even if this shelter is disturbed by tumor penetration. The delivery of therapeutic levels of drugs to the brain is an important challenge, due to the presence of the BBB. Previous researches have inspected several probable mechanisms by which NPs could transport drugs into the brain. ${ }^{34}$ They detected that poly (butylcyanoacrylate) (PBCA) NPs do not cause nonspecific BBB disruption, but rather work concomitantly with plasma apolipoprotein $\mathrm{E}$ (apoE) to promote BBB crossing. ${ }^{35}$ The mechanism includes the adsorption of 

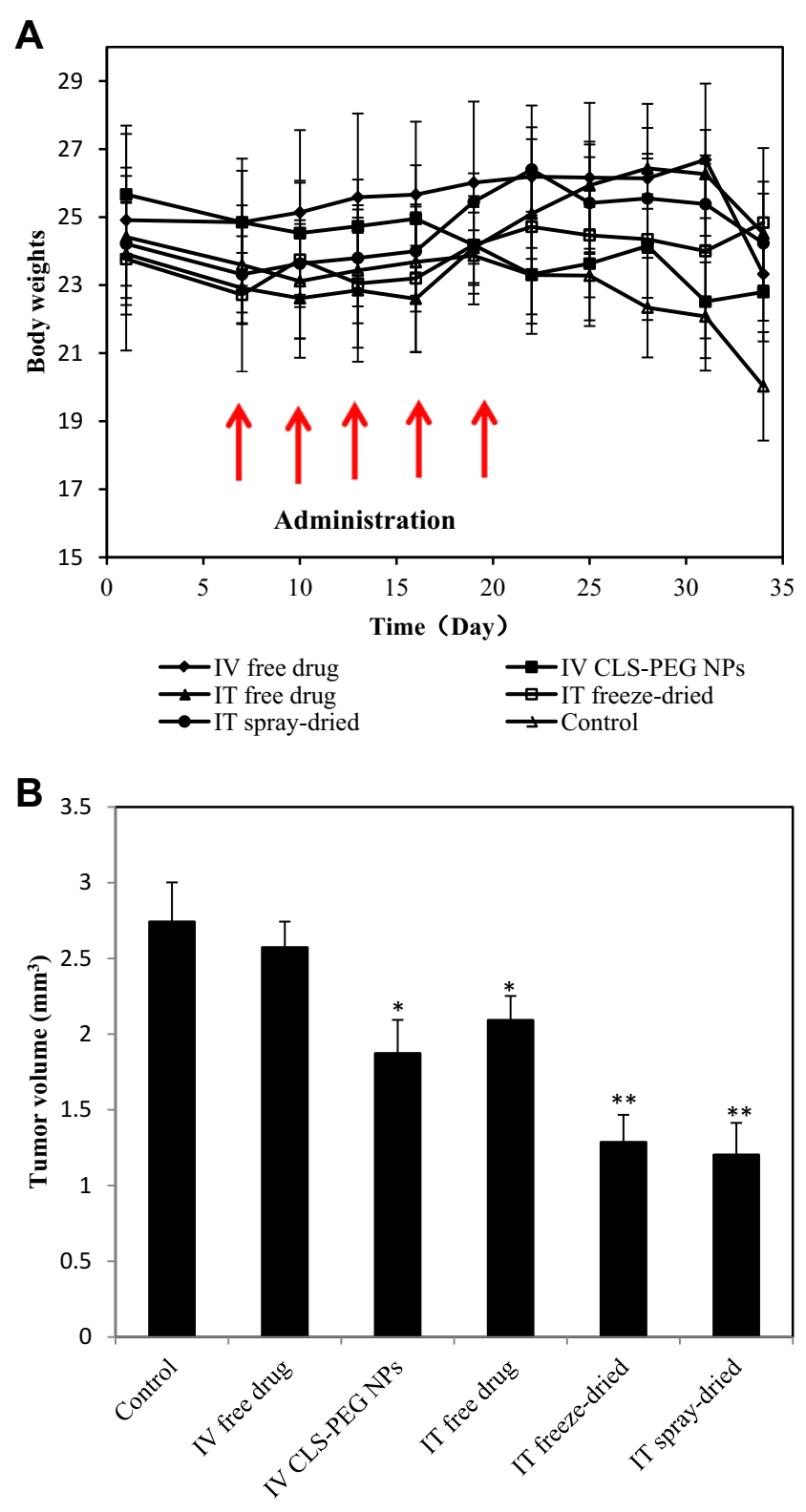

Figure 7 The in vivo antitumor effect and the variations in the body weights after intratracheal (IT) or intravenous (IV) administration of free DTX solution or DTXloaded CLS-PEG NPs at a dose of $10 \mathrm{mg} / \mathrm{kg}$ to the aggressive orthotopic mouse model of proximal lung cancer. (A) Body weights as a function of time. (B) Tumor volume on day 15 after the treatment of different DTX formulations. Mean $\pm S D$, $\mathrm{n}=6-10$. $* \mathrm{P}<0.05, * * \mathrm{P}<0.01$, compared with the negative control.

apoE from plasma, making receptor-mediated transcytosis via vascular endothelial cells the likely mechanism by which PBCA NPs cross the BBB. At present, the mechanism by which CLS-PEG NPs cross the BBB is not completely understood. Research has demonstrated that modifying PBCA NPs with PEG can avoid macrophage clearance, thus prolonging the circulation time. Although studies have established that almost all cholesterol in the central nervous system (CNS) is topically synthesized, and that there is a very little interchange of cholesterol through the intact
$\mathrm{BBB},{ }^{36-38}$ recent research has linked peripheral cholesterol in CNS disorders. ${ }^{39}$ The researchers surmised that cholesterol in the blood may be associated with chemical species that can expeditiously pass through the BBB. In addition, in our previous studies, ${ }^{22}$ we found that conjugating cholesterol to the surface of NPs increased the active transport of drugs across the BBB, via macropinocytosis.

For the free solution of DTX, a small amount of the drug could be delivered to the brain and was undetectable at all included time points (Figure 6). This was consistent with previous reports demonstrating that the $\mathrm{BBB}$ is practically impermeable to free DTX. ${ }^{40}$ Addition of CLS-PEG to PBCA NPs showed higher and more sustained distribution of DTX in the brain, relative to the free solution of DTX. Brain distribution data of DTX for CLS-PEG NPs after IT administration suggested that IT CLS-PEG NPs could enhance the content and half the time of DTX into the brain. This might be attributed to sustained DTX delivery after IT administration to the lung. Therefore, the enhanced content of DTX into the brain was probably caused by the combined function of cholesterol and PEG, and IT administration of CLS-PEG NPs presents as a practical and novel drug delivery system for both lung cancer and brain metastasis therapy.

\section{Conclusion}

Polymeric NPs have received much attention as promising carrier systems for lung cancer and brain metastases. In this study, we investigated, for the first time, the feasibility of using inhaled CLS-PEG NPs of DTX for sustained pulmonary delivery for lung cancer metastasis and brain metastasis. The spray- or freeze-dried NPs yielded sustained drug release in vitro. Inhalation evaluation data in vitro indicated that the inhalation formulation for CLS-PEG NPs had better inhalability. Compared to IV administration, pharmacokinetic data from this study suggested that the inhalation formulation prolonged the plasma concentration of DTX for more than $24 \mathrm{~h}$ and is more quickly and completely absorbed into the rat lung after IT administration. Further investigation of DTX concentrations in plasma demonstrated that the CLS-PEG NPs resulted in markedly higher concentrations than the free solution. Furthermore, freeze-dried powders were found to increase the $t_{1 / 2}$ and AUC by 2.3 and 6.5 fold compared to the free drug after IT administration, and spray-dried powders were found to increase the $t_{1 / 2}$ and AUC by 3.4 and 8.8 fold, respectively. After intrapulmonary administration of inhalation formulation in rats, DTX appeared to prolong the pulmonary absorption time. Freeze-dried and spray-dried powder 
CLS-PEG NPs improved the lung retention of the drug approximately 3.4 and 4.3 fold compared to the free drug, respectively. In addition, the inhalation formulation appeared to bypass the air-blood barrier and dispense to the brain in a sustained release way, showing promise for non-invasive systemic sustained release. Therefore, the result indicated that the freeze- and spray-powder CLS-PEG NPs have the potential to be used as a new treatment for the delivery of drugs that pass through the air-blood barrier and enter the brain, and they are efficient carriers for the treatment of lung cancer metastasis and brain metastasis.

\section{Funding}

This work was supported by Beijing Municipal Education Commission New Medicine Discipline Group Project [XK100270569], Foundation of Beijing of the training of outstanding talents in Excellent Young backbone individuals [2017000020124G269], Capital Medical University Research and Development Fund [PYZ2018123], National Key Research and Development Program of China [2016YFC0103909], Beijing Municipal Science \& Technology Commission project [Z161100000516008], Beijing hundred-thousand-Ten thousand Talents Project: Construction of brain-targeted PBCA nanocarrier based on PEG-cholesterol co-modification and its treatment of glioma (2018A04), Beijing Hospitals Authority Ascent Plan [DFL20190803], and Capital science and technology leading talent training project [Z191100006119017].

\section{Disclosure}

The authors report no conflicts of interest for this work.

\section{References}

1. Huang CY, Ju DT, Chang CF, et al. A review on the effects of current chemotherapy drugs and natural agents in treating non-small cell lung cancer. Biomedicine (Taipei). 2017;7(4):23. doi:10.1051/bmden/ 2017070423

2. Xiao F, Liu D, Guo Y, et al. Survival rate and prognostic factors of surgically resected clinically synchronous multiple primary non-small cell lung cancer and further differentiation from intrapulmonary metastasis. J Thorac Dis. 2017;9(4):990-1001. doi:10.21037/jtd.2017.03.59

3. Hu X, Yang FF, Liao YH. Pharmacokinetic considerations of inhaled pharmaceuticals for systemic delivery. Curr Pharm Design. 2016;22 (17):2532-2548. doi:10.2174/1381612822666160128150005

4. Janssen R, Piscaer I, Wouters EF. Inhalation therapy for repairing damaged elastin fibers and decelerating elastinolysis in chronic obstructive pulmonary disease. Expert Rev Respir Med. 2018;12 (5):349-360. doi:10.1080/17476348.2018.1460206

5. Sandip S, Hajare A, More H, et al. Lung delivery of nanoliposomal salbutamol sulfate dry powder inhalation for facilitated asthma therapy. J Liposome Res. 2019;29(4):332-342. doi:10.1080/089821 04.2018 .1531022
6. Abdelaziz HM, Gaber M, Abd-Elwakil MM, et al. Inhalable particulate drug delivery systems for lung cancer therapy: nanoparticles, microparticles, nanocomposites and nanoaggregates. $J$ Control Release. 2018;269:374-392. doi:10.1016/j.jconrel.2017.11.036

7. Ahmad N, Ahmad R, Alam MA, et al. Enhancement of oral bioavailability of doxorubicin through surface modified biodegradable polymeric nanoparticles. Chem Cent J. 2018;12(1):65. doi:10.1186/ s13065-018-0434-1

8. Ahmad N, Alam MA, Ahmad R, et al. Improvement of oral efficacy of irinotecan through biodegradable polymeric nanoparticles through invitro and invivo investigations. $J$ Microencapsul. 2018;35 (4):327-343. doi:10.1080/02652048.2018.1485755

9. Ahmad N, Ahmad R, Alam MA, et al. Daunorubicin oral bioavailability enhancement by surface coated natural biodegradable macromolecule chitosan based polymeric nanoparticles. Int $J$ Biol Macromol. 2019;128:825-838. doi:10.1016/j.ijbiomac.2019.01.142

10. Ahmad N, Al-Subaie AM, Ahmad R, et al. Brain-targeted glycyrrhizic-acid-loaded surface decorated nanoparticles for treatment of cerebral ischaemia and its toxicity assessment. Artif Cells Nanomed Biotechnol. 2019;47(1):475-490. doi:10.1080/21691 401.2018.1561458

11. Xu KF, Jia HR, Zhu YX, et al. Cholesterol-modified dendrimers for constructing a tumor microenvironment-responsive drug delivery system. ACS Biomater Sci Eng. 2019;5(11):6072-6081. doi:10. 1021/acsbiomaterials.9b01386

12. Chen EM, Quijano AR, Seo YE, et al. Biodegradable PEG-poly $(\omega$-pentadecalactone-co-p-dioxanone) nanoparticles for enhanced and sustained drug delivery to treat brain tumors. Biomaterials. 2018;178:193-203. doi:10.1016/j.biomaterials.2018.06.024

13. Rattan R, Bhattacharjee S, Zong H, et al. Nanoparticle-macrophage interactions: a balance between clearance and cell-specific targeting. Bioorg Med Chem. 2017;25(16):4487-4496. doi:10.1016/j.bmc.2017. 06.040

14. Liu X, Zhang Z, Jiang Y, et al. Novel PEG-grafted nanostructured lipid carrier for systematic delivery of a poorly soluble anti-leukemia agent Tamibarotene: characterization and evaluation. Drug Deliv. 2015;22(2):223-229. doi:10.3109/10717544.2014.885614

15. Sharif Y, Jumah F, Coplan L, et al. Blood brain barrier: a review of its anatomy and physiology in health and disease. Clin Anat. 2018;31 (6):812-823. doi: $10.1002 / \mathrm{ca} .23083$

16. Fan $\mathrm{CH}$, Ting CY, Chang YC, et al. Drug-loaded bubbles with matched focused ultrasound excitation for concurrent blood-brain barrier opening and brain-tumor drug delivery. Acta Biomater. 2015;15:89-101. doi:10.1016/j.actbio.2014.12.026

17. Rafiei P, Haddadi A. Docetaxel-loaded PLGA and PLGA-PEG nanoparticles for intravenous application: pharmacokinetics and biodistribution profile. Int $J$ Nanomed. 2017;12:935-947. doi:10.2147/IJN. S121881

18. Yan J, Wang Y, Jia Y, et al. Co-delivery of docetaxel and curcumin prodrug via dual-targeted nanoparticles with synergistic antitumor activity against prostate cancer. Biomed Pharmacother. 2017;88:374-383. doi:10.1016/j.biopha.2016.12.138

19. He C, Cai P, Li J, et al. Blood-brain barrier-penetrating amphiphilic polymer nanoparticles deliver docetaxel for the treatment of brain metastases of triple negative breast cancer. $J$ Control Release. 2017;246:98-109. doi:10.1016/j.jconrel.2016.12.019

20. Wang Q, Alshaker H, Böhler T, et al. Core shell lipid-polymer hybrid nanoparticles with combined docetaxel and molecular targeted therapy for the treatment of metastatic prostate cancer. Sci Rep. 2017;7 (1):5901. doi:10.1038/s41598-017-06142-x

21. Sun TM, Du JZ, Yao YD, et al. In-vitro cytotoxicity and combination effects of the docetaxel-conjugated and doxorubicin-conjugated poly (lactic acid)-poly(ethylene glycol)-folate-based polymeric micelles in human ovarian cancer cells. J Pharm Pharmacol. 2017;69 (2):151-160. doi:10.1111/jphp.12675 
22. Hu X, Yang FF, Liao YH, et al. Cholesterol-PEG co-modified poly (N-Butyl) cyanoacrylate nanoparticles for brain delivery: in vitro and in vivo evaluations. Drug Deliv. 2017;24(1):121-132. doi:10.1080/ 10717544.2016.1233590

23. Raliya R, Saha D, Chadha TS, et al. Non-invasive aerosol delivery and transport of gold nanoparticles to the brain. Sci Rep. 2017;7:44718. doi:10.1038/srep44718

24. da Luz CM, Boyles MS, Falagan-Lotsch P, et al. Poly-lactic acid nanoparticles (PLA-NP) promote physiological modifications in lung epithelial cells and are internalized by clathrin-coated pits and lipid rafts. J Nanobiotechnol. 2017;15(1):11. doi:10.1186/s12951-0160238-1

25. Youngren-Ortiz SR, Hill DB, Hoffmann PR, et al. Development of optimized, inhalable, gemcitabine-loaded gelatin nanocarriers for lung cancer. J Aerosol Med Pulm Drug Deliv. 2017;30(5):299-321. doi:10.1089/jamp.2015.1286

26. Wang H, George G, Bartlett S, et al. Nicotine hydrogen tartrate loaded chitosan nanoparticles: formulation, characterization and in vitro delivery from dry powder inhaler formulation. Eur J Pharm Biopharm. 2017;113:118-131. doi:10.1016/j.ejpb.2016.12.023

27. Wang Z, Gupta SK, Meenach SA. Development and physicochemical characterization of acetalated dextran aerosol particle systems for deep lung delivery. Int J Pharm. 2017;525(1):264-274. doi:10.1016/j. ijpharm.2017.04.052

28. Gill KK, Nazzal S, Kaddoumi A. Paclitaxel loaded $P_{56} G_{5000}-D S P E$ micelles as pulmonary delivery platform: formulation characterization, tissue distibution, plasma pharmacokinetics, and toxicological evaluation. Eur J Pharm Biopharm. 2011;79(2):276-284. doi: 10.1016/j.ejpb.2011.04.017

29. Goldberg SB, Contessa JN, Omay SB, et al. Lung cancer brain metastases. Cancer J. 2015;21(5):398-403. doi:10.1097/PPO.0000 000000000146

30. Aleshin VA, Karakhan VB, AKh B, et al. Lung cancer brain metastases - the role of neurosurgery. Opuholi Golovy I Šei. 2016;6:42-49. doi:10.17650/2222-1468-2016-6-2-42-49
31. Lowery FJ, Yu D. Brain metastasis: unique challenges and open opportunities. Biochim Biophys Acta Rev Cancer. 2017;1867 (1):49-57. doi:10.1016/j.bbcan.2016.12.001

32. Waqar SN, Samson PP, Robinson CG, et al. Non-small-cell lung cancer with brain metastasis at presentation. Clin Lung Cancer. 2018;19(4):373-379. doi:10.1016/j.cllc.2018.01.007

33. Chamberlain MC, Baik CS, Gadi VK, et al. Systemic therapy of brain metastases: non-small cell lung cancer, breast cancer, and melanoma. Neuro Oncol. 2017;19(1):i1-i24. doi:10.1093/neuonc/now197

34. Kreuter J. Nanoparticle systems for brain delivery of drugs. Adv Drug Deliv Rev. 2001;47(1):65-81. doi:10.1016/S0169-409X(00)00122-8

35. Koffie RM, Farrar CT, Saidi LJ, et al. Nanoparticles enhance brain delivery of blood-brain barrier-impermeable probes for in vivo optical and magnetic resonance imaging. Proc Natl Acad Sci USA. 2011;108(46):18837-18842. doi:10.1073/pnas.1111405108

36. Dietschy JM, Turley SD. Cholesterol metabolism in the brain. Curr Opin Lipidol. 2001;12(2):105-112. doi:10.1097/00041433-20010400000003

37. Jia H-R, Zhu Y-X, Xu K-F, et al. Plasma membrane-anchorable photosensitizing nanomicelles for lipid raft-responsive and light-controllable intracellular drug delivery. $J$ Control Release. 2018;286:103-113. doi:10.1016/j.jconrel.2018.07.027

38. Jia HR, Zhu YX, Chen Z, et al. Cholesterol-assisted bacterial cell surface engineering for photodynamic inactivation of gram-positive and gram-negative bacteria. ACS Appl Mater Interfaces. 2017;9 (19):15943-15951. doi:10.1021/acsami.7b02562

39. Reed B, Villeneuve S, Mack W, et al. Associations between serum cholesterol levels and cerebral amyloidosis. JAMA Neurol. 2014;71 (2):195-200. doi:10.1001/jamaneurol.2013.5390

40. Bhaskar S, Tian F, Stoeger T, et al. Multifunctional nanocarriers for diagnostics, drug delivery and targeted treatment across blood-brain barrier: perspectives on tracking and neuroimaging. Part Fibre Toxicol. 2010;7(3):1-25. doi:10.1186/1743-8977-7-3
International Journal of Nanomedicine

\section{Publish your work in this journal}

The International Journal of Nanomedicine is an international, peerreviewed journal focusing on the application of nanotechnology in diagnostics, therapeutics, and drug delivery systems throughout the biomedical field. This journal is indexed on PubMed Central, MedLine, CAS, SciSearch ${ }^{\mathbb{R}}$, Current Contents ${ }^{\mathbb{R}} /$ Clinical Medicine,
Journal Citation Reports/Science Edition, EMBase, Scopus and the Elsevier Bibliographic databases. The manuscript management system is completely online and includes a very quick and fair peer-review system, which is all easy to use. Visit http://www.dovepress.com/ testimonials.php to read real quotes from published authors. 